https://doi.org/10.48009/1_iis_2006_299-304

\title{
THE CASE FOR E-HEALTH IN THE INFORMATION SYSTEMS CURRICULUM
}

\author{
E. Vance Wilson, University of Wisconsin-Milwaukee, wilsonv@uwm.edu
}

\begin{abstract}
Worldwide, e-health has emerged as a fast-growing, transformational technology. However, no academic discipline currently provides a comprehensive curriculum in design, development, and administration of e-health applications. Adding $e$ health as an IS concentration offers numerous strategic benefits, assuming that certain structural barriers can be overcome.
\end{abstract}

Keywords: Consumer Health Informatics, HumanComputer Interaction, Personal Health Records, EServices, E-Commerce

\section{INTRODUCTION}

E-health has emerged as a transformational technology, changing the way people acquire health information and offering new levels of healthcare to underserved populations. A recent Harris Interactive report finds 117 million Americans access the Internet for health-related information, and $85 \%$ of these individuals conducted an information search within the month prior to being surveyed [7]. Growth of e-health has been slower outside of the developed nations, but future expansion appears likely as the World Health Organization and similar groups are now mobilizing to increase availability of e-health in developing nations $[8,17]$.

Yet e-health designers, developers, and administrators are necessarily self-trained in at least some portions of their work. No academic discipline currently offers a comprehensive curriculum that integrates fields underlying e-health, which include healthcare, human-computer interaction (HCI), and eservices. Because practitioners tend to build applications from the perspective of their personal expertise, lack of training could limit the success of e-health.

Most healthcare providers are now invested in ehealth as a key component of organizational strategy $[10,11]$. To meet the need for trained staff to support these investments, it is important that comprehensive e-health training programs be created at both the undergraduate and graduate level. Potentially, such programs could be located in schools of health sciences or schools of engineering and computer science. However, I present the case in this paper that IS departments may provide the best home for ehealth training.

The paper proceeds as follows. Three current e-health paradigms are reviewed and a user-centered perspective incorporating their best practices is presented. Next, the structural components of personal health informatics are described and a model is developed for implementation to support an ehealth concentration within the IS curriculum. The concluding section outlines strategic opportunities and potential obstacles to success.

\section{PARADIGMS OF E-HEALTH}

Most definitions of e-health focus on the convergence of healthcare and Internet technology [13]. Practical experience shows that the bulk of e-health users are receivers of medical care rather than providers [7]. For this reason, I focus here on e-health paradigms that are directed toward patients, caregivers, and other laypersons rather than paradigms directed toward healthcare providers, such as the telemedicine paradigm in which physicians and staff consult remotely with medical peers. From the lay perspective, three paradigms have played an important role in developing e-health to its current state: E-commerce, personal health records, and consumer health informatics.

E-Commerce paradigm. Many of the pioneers of ehealth operated within an e-commerce paradigm, in which vendors expect to profit from users paying directly for products and services acquired through the site or from advertisers paying for exposure to users. Typically, vendors were not affiliated with healthcare providers, so they could not deliver services that link individuals with their own physician, clinic, or pharmacy. Few of these vendors survived the dot-com shakeout, although WebMD is a notable exception.

Personal health record (PHR) paradigm. A second approach to e-health based initially on profit motives is the personal health record (PHR) paradigm. The PHR describes digitized health records that are owned and managed by individuals [1]. Demand for 
commercial PHRs has been low [15] but public awareness of PHRs has risen dramatically as a result of massive human displacement and damage to healthcare facilities that was sustained in recent hurricanes [6].

Consumer health informatics (CHI) paradigm. Healthcare provider organizations did not participate strongly in pioneering stages of e-health development, but they have been instrumental in developing e-health within a CHI paradigm. CHI is "a branch of medical informatics that analyzes consumers' needs for information; studies and implements methods for making information accessible to consumers; and models and integrates consumers' preferences into medical information systems" [2]. Although the CHI paradigm is designed to address needs of the individual user, it does this from an organizational perspective in which users are viewed primarily as passive consumers rather than active suppliers of information. For this reason, providing PHRs and integrating external patient data typically are not high priorities for e-health created within the $\mathrm{CHI}$ paradigm.

\section{Personal Health Informatics: A New Perspective on E-Health}

Each of these three paradigms responds to some needs in the population of e-health users. However, none addresses the total range of needs that have been identified. These include communicating with physicians and clinical staff, arranging services (e.g., scheduling appointments and renewing prescriptions), checking bills and making payments, viewing lab results, obtaining records of procedures, tests, and immunizations, receiving online alerts, monitoring chronic health conditions, and interacting with online support communities (e.g., patient chat groups), in addition to accessing encyclopedic health information [3, 5, 16]. Further, individuals want the ability to control their personal data, to ensure that record-keeping aspects of e-health are interoperable and portable, and to be assured of privacy and security [15].

In order to capture the complete set of knowledge and skills necessary to create truly encompassing ehealth, a new perspective has been proposed to integrate best practices of the three paradigms discussed above. This perspective has been named personal health informatics (PHI) in recognition of its user-centered focus, in which e-health design, development, and administration are driven by the needs of individual users taking the role of information provider as well as information consumer. PHI is defined as the knowledge, skills, practices, and research perspectives necessary to develop e-health that is effective, efficient, encompassing, and user-centered [18].

\section{PHI AS AN IS CONCENTRATION}

Four structural components define the content of PHI within three focal areas, as shown in Figure 1. Web e-service infrastructure comprises the hardware, software, and networking capabilities that support ehealth functions. Because e-health is primarily service-oriented, the informatics focus in PHI centers on infrastructure that is specialized for e-service presentation and delivery. Personal health management and user-centered development support the personal focus that PHI presents to individual users. User-centered development methods provide tools for eliciting user needs, designing solutions, and evaluating the utility of these solutions in meeting user needs. Personal health management addresses individual practices as well as psychological, social, and cultural aspects of managing, storing, and retrieving personal health information. Personal health management and the health informatics domain combine in the healthcare focus of PHI. Content within the health informatics domain addresses the skills, knowledge, and surrounding use of IT within the subject health area(s).

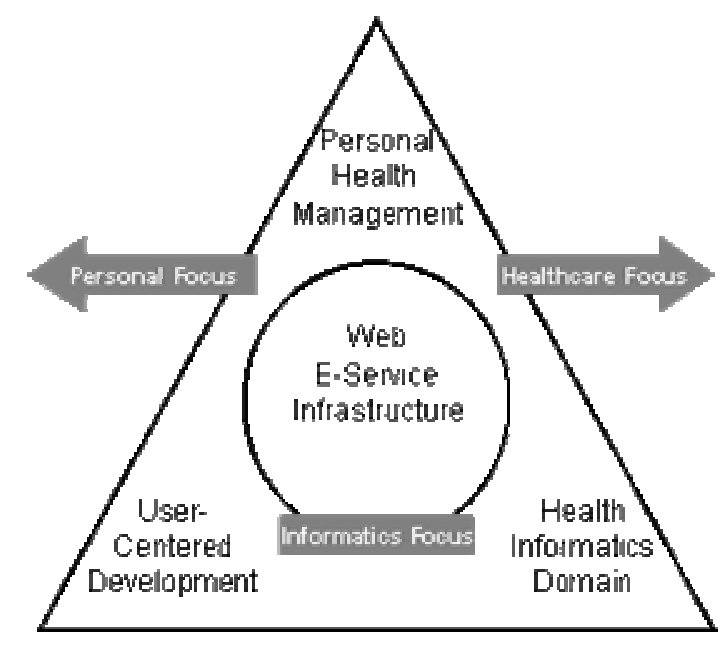

Figure 1. Conceptual Model of Key PHI Structural Components

For students to enter the workforce with comprehensive preparation in e-health design, 
development, or administration, training will be needed in each of the structural components of PHI that are presented in Figure 1. None of these areas is beyond the grasp of undergraduate or graduate students; however, the combination of content areas represents a set of specializations that are not commonly combined in current curricula. To students, the IS curriculum can provide a solid foundation on which to base an effective e-health curriculum.

\section{E-Service Web Infrastructure Curriculum}

E-health in the PHI paradigm is essentially a form of e-service, defined as services provided over electronic networks such as the Internet [14]. Thus, texts that focus on development and administration of web infrastructure for e-services will be appropriate to PHI. Texts that address the general topic of ecommerce typically are less applicable, as large portions of these dwell on factors that are not central to e-health, such as general business models, marketing and consumer behavior issues, and methods for increasing online sales. Web infrastructure changes rapidly, so texts in this area must not be allowed to become stale. New texts should be chosen based upon inclusion of emerging technologies, such as mobile devices, speech recognition, and natural language parsers, as well as effective coverage of more mature technologies, such as XHTML, database connectivity, and network communications.

\section{User-Centered Development Curriculum}

User-centered software development refers to a process that incorporates the user viewpoint, assesses user needs, and validates that user needs are met. There are two complementary approaches to this process that will be valuable to students of PHI. The first of these is the design guide approach. Design guides emphasize generic or context-driven design principles [9]. These are valuable in establishing general guidelines in conventional use of design features and in broadening students' appreciation of ways that others' perspectives may differ from their own.

The second approach emphasizes planning and evaluation processes of user interface development. For example, the SALVO method [19] guides students through five development stages. The first three of these are planning stages in which designers Specify user needs, Adopt a technology-specific design guide, and Leverage appropriate matches between technology and user needs to enhance user abilities and support user disabilities. Once planning stages are initially completed, developers perform Visualization techniques including mock-ups to elicit user feedback early in the development cycle. Visualization is followed by an Observation stage in which designers observe and evaluate attempts by users to perform representative tasks using the mockup or completed software. SALVO takes an iterative approach to development, and it is accepted throughout the development cycle that prior stages and sequences of stages will be repeated as necessary. The design process approach provides Ehealth students with a methodology and specific tools for customizing e-health to meet the needs of a specific user audience, which may differ substantially, for example, between a macular degeneration support group and the general public.

\section{Personal Health Management Curriculum}

Personal health management addresses how people plan and organize health-related activities. It focuses on strategies used for storing and retrieving health information, such as insurance forms, prescription instructions, and scheduled medical appointments. Currently, little personal health management is performed with the aid of computers, but numerous factors are converging to motivate individual use of PHRs that can be delivered as part of e-health applications [6]. Because the ability to manage health activities online is very important to patients and their caregivers [15], the study of behavioral, social, and technical factors underlying personal health management must be considered a key part of ehealth training.

Personal health management is a relatively recent field, and for this reason it may be too early to look for texts that are specific to the area. However, good empirical studies and cases are available that can serve as the basis for productive courses using case methods of instruction. A recent example is a study that identifies four key health information management strategies that individuals apply in their own homes [12]. If adopted as a teaching case, this exemplar study would prompt e-health students to consider the effects of trade-offs between information accessibility and visibility, implications of the high degree of reliance individuals place on paper-based records, and design decisions that could help align electronic records to support the differentiated storage strategies that individuals are found to prefer. 


\section{Health Informatics Domain Curriculum}

The health informatics domain encompasses use of IT to support delivery of healthcare services (including communication, coordination, logistics, and other business processes) as well as applicable practices and procedures that surround use of IT in the healthcare setting. Topics in the health informatics domain include the following:

- History of the origins of health/medical informatics

- Medical nomenclature standards, e.g., systemized nomenclature of medicine (SNOMED)

- Medical data communication methods and standards, e.g., health level seven (HL7)

- Medical information systems, including various subtypes, e.g., hospital IS, clinical support systems, and clinical office information systems

- Electronic patient records, including contemporary standards and perspectives

- Legal requirements, e.g., health insurance portability and accountability act (HIPAA)

Most topics in this domain may be covered effectively by use of current health/medical informatics texts. Because of the network orientation of e-health applications, however, it is essential to emphasize medical data communication methods and standards.

\section{Organization of the E-Health Concentrations in IS}

In order to achieve basic competence in the fields underlying e-health, IS students should complete one three-unit course in each of the domain areas. One course may be adapted from an existing course in the curriculum that addresses e-commerce and/or web development. A suggested curriculum organization is mapped in Figure 2 to the IS 2002 undergraduate course architecture and sequence [4]. A graduate curriculum would follow a similar structure of course sequencing as the undergraduate program. The following courses are recommended for implementing an e-health concentration:

- E-Service Web Infrastructure (3 units). Course prerequisites: IS 2002.1, Fundamentals of Information Systems (this course adapts IS 2002.2, "E-Business Strategy, Architecture, \& Design" to address e-service topics).

- User-Centered Web Development (3 units). Course prerequisite: IS 2002.5, Programming, Data, File and Object Structures, psychology/sociology general education requirements.

- Personal Health Management (3 units). Course prerequisite: IS 2002.8, Physical Design and Implementation with DBMS, psychology/sociology general education requirements.

- Health Informatics (3 units). Course prerequisite: IS 2002.8, Physical Design and Implementation with DBMS.

Following the suggested organization, an e-health concentration will account for nine units in addition to the core undergraduate or graduate IS curriculum.

\section{CONCLUSION: STRATEGIC OPPORTUNITIES AND OBSTACLES}

As a result of layoffs in the IS profession that accompanied completion of year 2000 conversions and the dot-com shakeout, IS academic program student enrollments have plummeted. IS and other technology-based disciplines have been subject to significant historic cycles of "boom and bust," so the current depressed enrollments are not entirely unexpected. Nonetheless, it is a troublesome situation as IS faculties struggle to defend resources, and campus administrators come to look upon IS departments as excess overhead.

Spending in health IT is increasing faster than most other IT areas. In response, enrollments in traditional health informatics programs are growing and a number of new programs have been launched in the U.S. Yet specialized training in e-health is rarely offered by these programs. Adding and promoting ehealth as an IS concentration could help student enrollments grow in the near term and could insulate IS departments from enrollment cycles in the longer term.

Because the IS discipline focuses on meeting needs of individuals within organizational settings, IS departments are uniquely qualified to teach prerequisite subjects as well as e-service infrastructure and user-centered development. Thus, the key criterion for IS faculties to offer an e-health concentration is to arrange for instructional coverage in areas of personal health management and health informatics courses. Ideally, instructors in these areas can be integrated into departmental tenure-track faculty. However, IS faculty champions and departmental commitment are essential in order to retain faculty who can effectively manage the ehealth concentration. Because the domains supporting e-health cross disciplinary boundaries, it 
is critical that tenure and promotion policies reward high-quality interdisciplinary research, teaching, and service.
Incorporating e-health into the IS curriculum can make good use of slack resources and also reinforce the image of IS as a forward-thinking and growthoriented discipline. I propose that these benefits are worth pursuing in the current enrollment downturn.

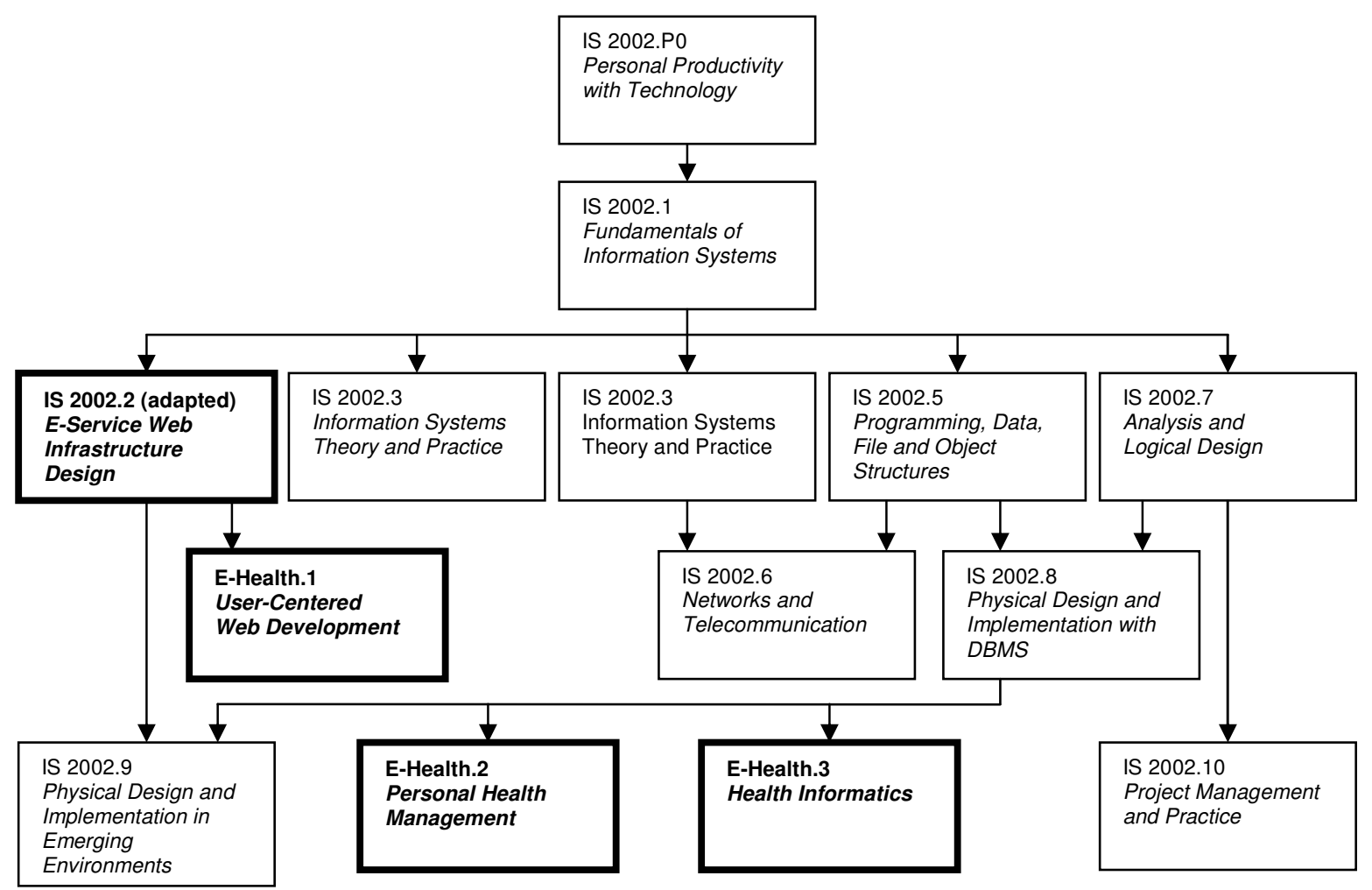

Figure 2. Suggested Sequence for Undergraduate IS Major with E-Health Concentration.

\section{REFERENCES}

1. AHIMA (2005). The role of the personal health record in the EHR. Journal of AHIMA, 76(7), 64A-64D.

2. Eysenbach, G. (2000). Consumer health informatics. British Medical Journal, 320(7251), 1713-1716.

3. Fox, S. (2005). Health information online. Pew Internet \& American Life Project. http://www.pewinternet.org

4. Gorgone, J. T., Davis, G. B., Valacich, J. S., Topi, H., Feinstein, D. L., \& Longenecker, H. E., Jr., (2002). IS 2002 model curriculum and guidelines for undergraduate degree programs in information systems. Communications of the
AIS, 11(1), 1-63.

5. Harris (2000). Healthcare satisfaction study. Harris Interactive/ARiA Marketing Final Report. http://www.harrisinteractive.com/news/downloa ds/HarrisAriaHCSatRpt.PDF.

6. Kloss, L. (2005). Greater urgency, sharper focus for PHRs. Journal of AHIMA, 76(10), 27.

7. Krane, D. (2005). Number of "cyberchondriacs" - U.S. adults who go online for health information - increases to estimated 117 million. Healthcare News, 8(5). http://www.harrisinteractive.com/news/newslette rs_healthcare.asp

8. Kwankam, S. Y. (2004). What e-health can offer. Bulletin of the World Health Organization, 82(10), 800-802. 
9. Lazar, J. (2001). User-centered web development. Sudbury, MA: Jones and Bartlett.

10. Lazarus, I. R. (2001). Separating myth from reality in e-health initiatives," Managed Healthcare Executive, June, 33-36.

11. Martin, S., Yen, D. C., \& Tan, J. K. (2002). Ehealth: Impacts of Internet technologies on various healthcare and services sectors. International Journal of Healthcare Technology and Management 4(1,2), 71-86.

12. Moen, A., \& Brennan, P. F. (2005). Health@Home: The work of health information management in the household (HIMH): Implications for consumer health informatics (CHI) innovations. Journal of the American Medical Informatics Association, 12(6), 648656.

13. Oh, H., Rizo, C., Enkin, M., \& Jadad, A. (2005). What is e-health(3): A systematic review of published definitions. Journal of Medical Internet Research, 7(1), article e1.

14. Rust, R., \& Lemon, K. N. (2001). E-service and the consumer. International Journal of $E$ Commerce, 5(3), 85-102.

15. Taylor, H. (2004). Two in five adults keep personal or family health records and almost everybody thinks this is a good idea: Electronic health records likely to grow rapidly. Health Care News, 4(10). http://www.harrisinteractive.com/news/newslette rs_healthcare.asp

16. Taylor, H., \& Leitman, R. (2002). Patient/physician online communication: Many patients want it, would pay for it, and it would influence their choice of doctors and health plans. Health Care News, 2(8). http://www.harrisinteractive.com/news/newslette rs_healthcare.asp

17. WHO (2005). E-health: Report by the Secretariat. World Health Organization, 58th World Health Assembly, 4/7/2005.

18. Wilson, E. V. (2006). Building better e-health through a personal health informatics pedagogy. International Journal of Health Information Systems and Informatics, 2(3).

19. Wilson, E. V., \& Connolly, J. R. (2000). SALVO: A basic method for user interface development. Journal of Informatics Education \& Research, 1(2), 29-39. 